\title{
ACHIEVING SIMPLICITY: A CONSIDERATION OF A SYSTEMATIC APPROACH
}

\author{
F. Pilz ${ }^{凶}$, S. Vajna and M. Schabacker \\ Otto von Guericke University Magdeburg, Germany \\ $\bowtie$ fabian.pilz@ovgu.de
}

\begin{abstract}
Design principles from the field of design engineering require that a product be designed as unambiguous, safe and simple as possible. Simplicity results on the one hand from an objective product-relevant side, on the other hand from the experience and knowledge of the user. A product that is perceived as simple by one person may seem complicated to another. From this, the questions arise, with which attributes simplicity can be described and how these are to be captured. In this paper, an evaluation system for the subjective attributes of simplicity is created using the fuzzy sets approach.
\end{abstract}

Keywords: complexity, evaluation, user-centred design, fuzzy sets, decision model

\section{Introduction}

Due to the ever-increasing variety of products, functional integration within a product and an increasing flood of information, a reduction of the resulting complexity is required almost everywhere. The aim of all developments is to utilize the possibilities of technical systems in order to enable people to overcome performance limits or to maintain or expand their capabilities. Design principles from the field of design engineering demand that a product shall be as simple as possible. When developing products, the product has to be unambiguous, simple and safe. While "safety" and "unambiguity" can be defined in relation to a certain environment by precise definitions, simplicity is usually characterized by fuzzy parameters. Current approaches to the evaluation of simplicity consist either in the reduction to deterministic values (Hartmann, 2013), which gives the evaluation model a strong abstraction from the real model, or in the use of unclear parameters, which divide the fuzzy term simplicity into further fuzzy terms (e.g. a simple assembly results from an easy assembly) (Feldhusen and Grote, 2013). The research question arises to what extent simplicity can be captured as subjective product characteristics and which methods serve as suitable tools for this purpose. The resulting paradigm shift inevitably leads to a change in conventional product development, as it leads to a need of adapted strategies and methods.

In this paper, we present a new concept for evaluating product simplicity. First, we give an overview of the definition of a simple product, to what extent different groups are to be considered, and which advantages simple products have. We discuss the individual attributes of simple products and their influence on each other. Based on this, the principle of fuzzy sets is described as a possible evaluation method for subjective attributes and explained within an example. We evaluate a simplicity index with the help of deterministic and fuzzy evaluation procedures. With this index, it is possible to divide the simplicity into different product subcategories. 


\section{Demand of simple products}

The first question that must be answered in this context is how the simplicity of a product is defined. A common definition of simplicity is often described by its relation to complicatedness and complexity. This has its origin in system theory (Hartmann, 2013), which defines a complicated system by the degree of diversity of the elements, their number and their interconnections. It is possible to simplify a complicated system by structuring and clustering. Thus, a complicated system can consist of a multitude of subsystems, which may be interpreted either as complicated or simple. The understanding of a complicated system depends on both experience and knowledge of the person, who interacts with the product. This is mostly not comprehensible for the non-expert, but can be taught. An example of this can be the acquisition of a driving license (Preim and Dachselt, 2015).

Complex systems also have a multitude of elements and connections between them. In addition, they are subject to seemingly random, dynamic changes that fluctuate over time. They are difficult to disassemble, calculate and organize (Pilz et al., 2018). By further exploring simplicity within product development, it is possible to identify a much larger number of research areas dealing with this topic).

Table 1. Research area of interest

\begin{tabular}{|c|c|c|}
\hline Research area & Core subject & Selected authors \\
\hline $\begin{array}{l}\text { Engineering } \\
\text { Design }\end{array}$ & $\begin{array}{l}\text { Structural complexity: Simplicity result from the } \\
\text { number of elements, the relationships between } \\
\text { elements and their boundary conditions }\end{array}$ & $\begin{array}{l}\text { (Pahl et al., 2007; Ehrlenspiel and } \\
\text { Meerkamm, 2013; Hubka, 1984) }\end{array}$ \\
\hline Product Design & $\begin{array}{l}\text { Variety of individual design elements influences the } \\
\text { perception of simplicity and complexity }\end{array}$ & $\begin{array}{l}\text { (Zeh, 2010; Schneider, 2005; } \\
\text { Seeger, 2005) }\end{array}$ \\
\hline Manufacturing & $\begin{array}{l}\text { Lean production: employee training, customer } \\
\text { involvement, low hierarchies }\end{array}$ & (Dombrowski and Mielke, 2015) \\
\hline $\begin{array}{l}\text { Assembly } \\
\text { Design }\end{array}$ & $\begin{array}{l}\text { Standardization, fragmentation and modularization } \\
\text { simplify assembly }\end{array}$ & (Womack et al., 1992) \\
\hline Maintenance & $\begin{array}{l}\text { Disassembly, Assembly structure, Types of } \\
\text { connection }\end{array}$ & $\begin{array}{l}\text { (Pahl et al., 2007; Ehrlenspiel and } \\
\text { Meerkamm, 2013) }\end{array}$ \\
\hline Usability & $\begin{array}{l}\text { Type of function execution, Effectiveness of } \\
\text { execution, Efficiency of execution, Satisfaction of } \\
\text { execution }\end{array}$ & $\begin{array}{l}\text { (Robier, 2016; Geis and Johner, } \\
\text { 2015; Choi and Lee, 2012) }\end{array}$ \\
\hline $\begin{array}{l}\text { User } \\
\text { Experience }\end{array}$ & $\begin{array}{l}\text { Types of product perception. Interplay of } \\
\text { expectation conformity and the mental model. Ease } \\
\text { of Use. }\end{array}$ & $\begin{array}{l}\text { (Preim and Dachselt, 2015; } \\
\text { Norman, 2013; Quirmbach, 2013) }\end{array}$ \\
\hline Management & $\begin{array}{l}\text { Structural shift, Insufficient transparency, Product } \\
\text { expansions, Complexity as know-how protection }\end{array}$ & (Olbrich and Battenfeld, 2005) \\
\hline $\begin{array}{l}\text { General } \\
\text { Simplification }\end{array}$ & The ten laws of simplicity, Life simplification & (Maeda, 2006; Helfrich, 2015) \\
\hline
\end{tabular}

The analysis of the different research areas in Table 1 shows that a simple product is defined differently depending on the respective research area. While in system theory a system is defined as simple because of the number of its components and the number of relationships between them, the usability of products is mainly evaluated by the quality of the user interface. The focus here is on the efficient handling of the products together with the respective product design (Hassenzahl, 2004). From the provider's point of view, both the producibility and the cost-effectiveness of the product is in the focus (Vajna, 2014). It can be concluded from this investigation that different approaches are pursued in achieving simplicity within the product life cycle (according to Urakami and Vajna, 2018), 
especially in distinguishing between the development process, i.e. the consideration of the provider (which covers developer, manufacturer, manager, salesperson etc.) and of the user (which covers the buyer as well). From the user's viewpoint a product is simple if the expected product benefits are available within a defined or rather expected time interval in an obvious and trouble-free manner and in which the product exhibits the expected range of functions. From the provider's point of view, a product can also appear to be simple if its profitability can be achieved quickly, as expected, and without disturbances (Pilz et al., 2018).

In this paper, we will distinguish between these two groups in describing simplicity. In general, it is necessary to differentiate between the provider and the user perspective. Since, as the definition shows, both perspectives have a very different focus on a product, an evaluation from only one view or a combination of both is not easily possible. However, in order to enable a comprehensive view of the entire product life cycle, both views are dealt with in this paper. Additional, complicatedness is regarded as a precursor of complexity, which can be counteracted by appropriate human centricity. In addition to considering what constitutes a simple product, it should also be noted why a systematic development of simple products is desirable. Achieving simplicity offers several advantages for the user when dealing with products, processes, and services (Brügger et al., 2013):

- Quick and better understanding of the product context, resulting in a fast learning of the usage of the product.

- Reducing the chance of operating errors to increase user satisfaction.

- A faster purchase decision for simple services and products.

- A higher user acceptance.

In addition to these user-specific advantages, which of course also make themselves felt in the sales of the product, simple products offer advantages that benefit the provider (Hartmann, 2013):

- Development and implementation of a simple product are influenced positively by simple processes and thus achieve results faster.

- Reduced assembly effort due to simplified shapes.

- Better comprehensibility due to simplified working principles and functional structures.

- Functional principles as well as simple forms support the predictability of both product performance and behaviour.

In summary, it can be concluded that, despite the many advantages of simple products, no uniform definition of a simple product prevails. On the one hand, this can be due to a narrow view on one's own field of research, on the other hand, to a mutual contradiction of the properties of simple products (Pilz et al., 2018).

\section{Attributes of simple products}

The different approaches to simple products shown in Table1 illustrate that simplicity has a certain diversity in terms of definition and development. From this aspect of the diversity of simplicity, it is questionable which characteristics can be used to evaluate product simplicity. To this end, opinions and assessments of experts from research and industry on the subject of simple products were questioned in a workshop during the DESIGN 2018 Conference in Dubrovnik/Croatia. The aim was to determine the causes and characteristics for a simple product using a selection of previously prepared mechanical and mechatronic products. A distinction between user and provider view was defined in advance. To simplify the evaluation, the 55 collected characteristics were used within predefined attributes based on the attributes of Integrated Design Engineering (IDE) (Vajna, 2015).

The attributes describe characteristics, properties and features of a product throughout the entire product life cycle. A distinction must be made between the product attributes, which are defined directly by the product, the so-called fulfilment attributes that make a statement about the quality of product performance and behaviour, and the benefit attributes, which define the ideal and material capabilities of the product. To simplify the product properties, four attributes have been defined for both the users and providers point of view, as shown in the following Figure 1. 


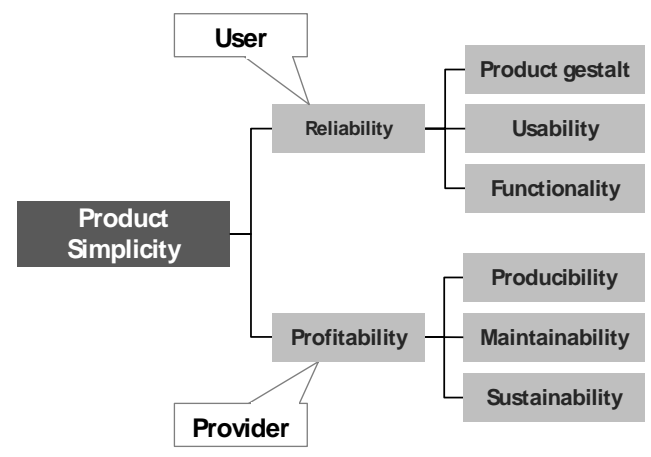

Figure 1. Attributes of simple products

The attributes of simple products are defined as follows, based on Vajna (2015):

- Product gestalt covers a product culture, identity and presence. It reflects the visual and emotional characteristics of the product and thus presents ("promises") both the product capability and the performance behaviour to the user.

- Usability describes in a broader sense the performance, use and quality of the interface. It is characterized by efficiency, effectiveness and satisfaction of the user.

- Functionality describes the ability of the product to meet a set of discrete requirements. A distinction must be made between type, level and quality of a function, and the mutual influences between the functions of a product.

- Reliability is a fulfilment attribute that is defined by the resulting quality of the product. It is characterized by expected conformity of product performance, behaviour, robustness (especially a minimum of operating errors and troubleshooting) and a long service life. As reliability covers the overall performance of the product, it is superior to the attributes (but this is not a statement for the weighting of the attributes).

When considering the provider's side, the focus is primarily on the entire product life cycle:

- Producibility provides all information necessary for the production of the product. It is a costoriented attribute. It defines under which logistical, technical and organizational conditions a product can be generated.

- Maintainability describes the ease with which a product can be maintained, adapted, or subjected to a new environment.

- Sustainability presents the ethical, ecological, and economical behaviour of the product during its complete life cycle in a global environment, for which it defines the ecological requirements.

- Profitability defines the economic aspects from the provider's point of view. It is the primary reason for new developments. Like reliability, profitability results from the overall product performance and behaviour.

\section{Fuzzy decision systems}

As mentioned in Section 1, the evaluation of simplicity is not possible solely through deterministic values. While the level of functionality or the life span can be described by sharp, deterministic values, attributes such as productgestalt and usability are mainly described by subjective and fuzzy values. The quality of the self-explanation is not only possible through the visual characteristics of a product. Self-explanation results from the experience and knowledge of the user, the associations (mental models) that the design of the product wants to address and the actual mental model of the user possesses (Norman, 2013). Usually, questions as to whether a product is self-explanatory or intuitive are answered with a linguistic evaluation, such as "good" or "bad". The valuation method of the Likert (Zeh, 2010) scale is often used to collect this information. In this, so-called items are evaluated within a given multi-level response scale with the help of fuzzy variables. It is very easy for people to give a linguistic assessment of a condition without setting clear boundaries. These evaluations are generally not based on a comprehensive theoretical knowledge, but on a 
summary of rules, which the evaluator subconsciously follows in his decision (Rommelfanger, 1993). It is questionable, however, how these fuzzy variables such as "beautiful" or "good" can be traced back to deterministic values. The aim is to establish a simplicity index, which includes both the objectively captured parameters and the user-dependent subjective ones. A comparison of the products to be evaluated requires a standardized form of all different value dimensions. Such standardization can be achieved by awarding points on a numerical scale of values, separated according to quantitative values and qualitative statements (Breiing and Knosala, 1997). While from the provider's point of view the attributes contain quantitative values, the evaluation of the usage of products must be based on qualitative statements. It is questionable how clearly definable states can be derived from fuzzy evaluations of a Likert scale.

Fuzzy decision systems, which do not rely on such distinct limits within evaluation variables, offer a remedy (Rommelfanger and Eickemeier, 2002). Examples for the use of such fuzzy decision systems in linguistic environments can be found under (Rommelfanger, 1993; Güllich, 1997; Pilz et al., 2018). In contrast to the classic quantity theory, in which a value can only be assigned to one set at a time, fuzzy sets can belong to more than one set by means of different affiliations. This means that a product can be considered simple to a certain extent and complex to another certain extent (Breiing and Knosala, 1997). Figure 2 shows the process of such a fuzzy decision system (Rommelfanger, 1993).

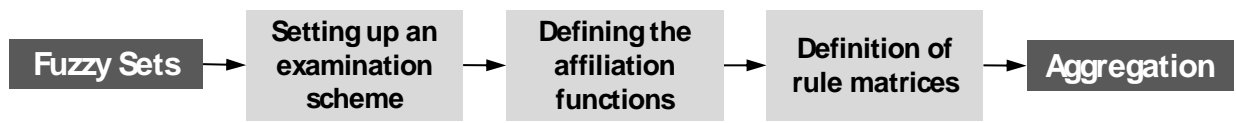

Figure 2. Structure of a fuzzy decision system

The first step is to create an examination scheme, which subdivides the mostly abstract and fuzzy variables into more easily comprehensible subcategories. The aim is to obtain an overall evaluation by aggregating the individual parameters. The attributes listed in Section 3 can be understood as an example of such a subdivision. For further use, an affiliation function must be defined for each subcategory. In contrast to the classic set definition, in which each element has a unique affiliation to a set, fuzzy elements can also only belong to a set to a certain degree (Rommelfanger and Eickemeier, 2002). These affiliation functions represent the value of a linguistic statement versus a deterministic value. Figure 3 shows examples of the affiliation functions of the subcategories effectiveness, efficiency and self-explanation of the attribute usability. The affiliation functions are rules formulated by experts, which describe the circumstance of the assessment (Rommelfanger, 1993). The affiliation functions shown in Figure 3 are the results of investigations of projects within the IDE master course at our university for the Effectiveness and Efficiency. Within these projects, a product is developed from product idea to prototype. A big focus is on a user-centred development and thus offers a good approach to the creation of affiliation functions from the user's point of view.

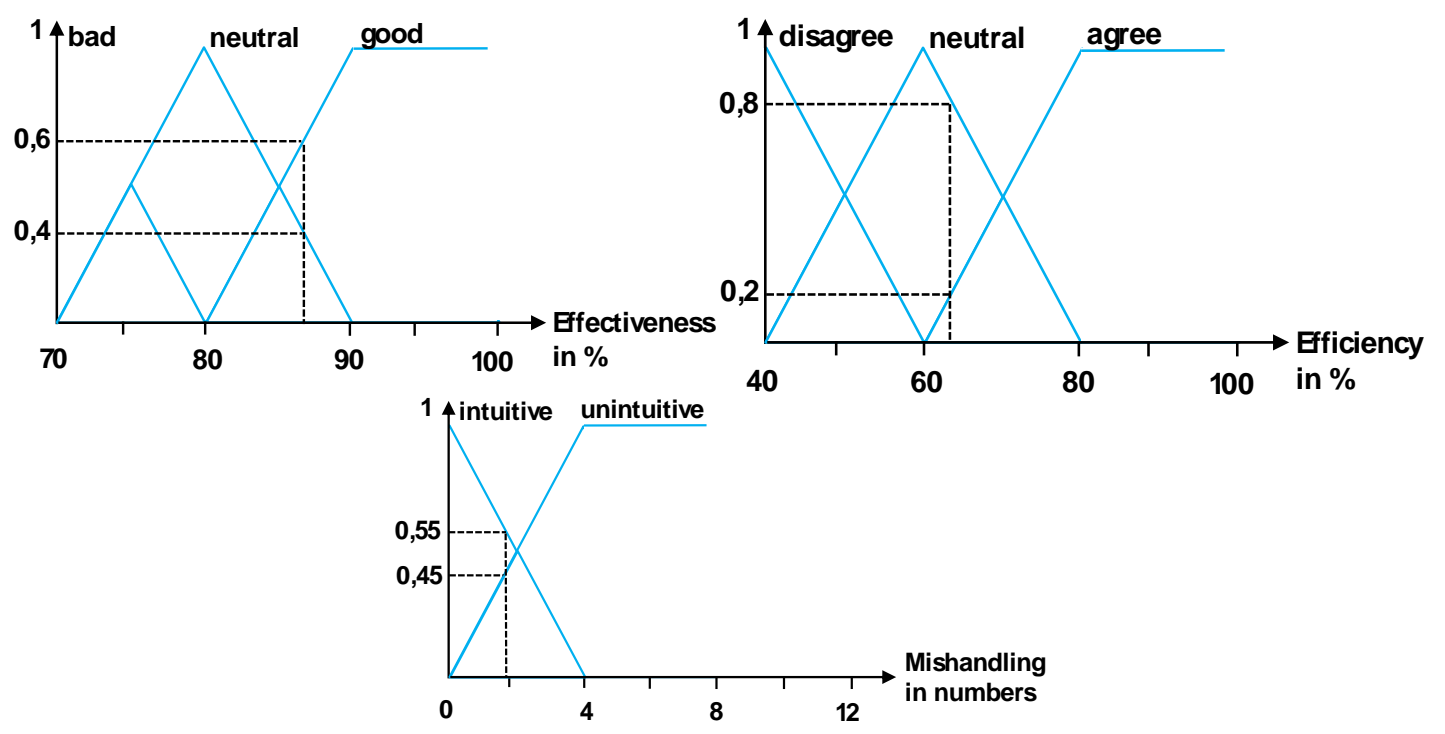

Figure 3. Affiliation function of the effectiveness, efficiency and mishandling 
The affiliation function defines the affiliation of a set of a linguistic formulation within a defined interval. The example of effectiveness shows that at least $80 \%$ of the expected target has been achieved if the effectiveness is "good". At the same time, however, they also belong to the group of those assessed as "neutral", but to a much lesser extent. $85 \%$ belong equally to 0.5 to the amount of neutral effectiveness and to 0.5 to the amount of good effectiveness.

In order to derive an overall statement about the usability from these rules, a rule matrix is necessary that interprets the individual evaluation options. This rule matrix varies in size depending on the number of possible answers and the number of areas examined due to the increasing combinatorial possibilities. The expert who draws up the table of rules or the team of experts must define the affiliation functions in such a way that it reflects his subjective perception correctly. As this is experience knowledge, one will have to be satisfied with an approximate description. This is also expressed in the fact that mostly simple functional forms are used and the same description pattern appears again (Rommelfanger, 1993). In the example shown in Figure 3, a total of eighteen possible combinations result, which can arise as subset for usability, shown in Table 2.

Table 2. Rule matrix for usability evaluation

\begin{tabular}{|c|c|c|c|}
\hline Effectiveness & Efficiency & $\begin{array}{c}\text { Self - } \\
\text { Explanatory }\end{array}$ & Usability \\
\hline bad & disagree & unintuitive & very bad \\
\hline bad & neutral & unintuitive & very bad \\
\hline bad & agree & unintuitive & bad \\
\hline bad & disagree & intuitive & bad \\
\hline bad & neutral & intuitive & neutral \\
\hline bad & agree & intuitive & neutral \\
\hline neutral & disagree & unintuitive & very bad \\
\hline neutral & neutral & unintuitive & bad \\
\hline neutral & agree & unintuitive & neutral $(0,4 ; 0,8 ; 0,55)=1,75 / 14,5 \%$ \\
\hline neutral & disagree & intuitive & neutral \\
\hline neutral & neutral & intuitive & neutral $(0,4 ; 0,8 ; 0,45)=1,65 / 13,8 \%$ \\
\hline neutral & agree & intuitive & very good $(0,4 ; 0,2 ; 0,45)=1,05 / 8,7 \%$ \\
\hline good & disagree & unintuitive & bad \\
\hline good & neutral & unintuitive & neutral $(0,6 ; 0,8 ; 0,55)=1,95 / 16,2 \%$ \\
\hline good & agree & unintuitive & good $(0,6 ; 0,2 ; 0,55)=1,35 / 11,2 \%$ \\
\hline good & disagree & intuitive & good \\
\hline good & neutral & intuitive & very good $(0,6 ; 0,8 ; 0,45)=1,85 / 15,4 \%$ \\
\hline good & agree & intuitive & very good $(0,6 ; 0,2 ; 0,45)=1,25 / 10,4 \%$ \\
\hline
\end{tabular}

If we assume, for example, that the effectiveness of a product is estimated at $87 \%$, the efficiency at $64 \%$ and the self-explanation with the average number of operating errors at 2 (see Figure 3), then we have a total of 8 affiliations for the usability of the product. For the "very good" usability set, there is a good effectiveness of 0.6, a good effectiveness of 0.2 and an intuitive handling of 0.45 . If the other affiliations are taken into account and standardized by their total sum, an aggregation is possible. This results in a bad usability of $14.5 \%$, a neutral usability of $40 \%$, a good usability of $11 \%$ and a very good usability of $34.5 \%$. Figure 4 gives a graphical overview of the resulting conditions. It should be noted that these values are not probabilities of usability, but represent allocations to the various quantities.

In order to form a final aggregation of the affiliations, it makes sense to carry out a so-called defuzzification in the last step. By forming the centroid of the area, the distribution can be returned to a single value (represented by the dash-point line in Figure 4) (Rommelfanger, 1993). 


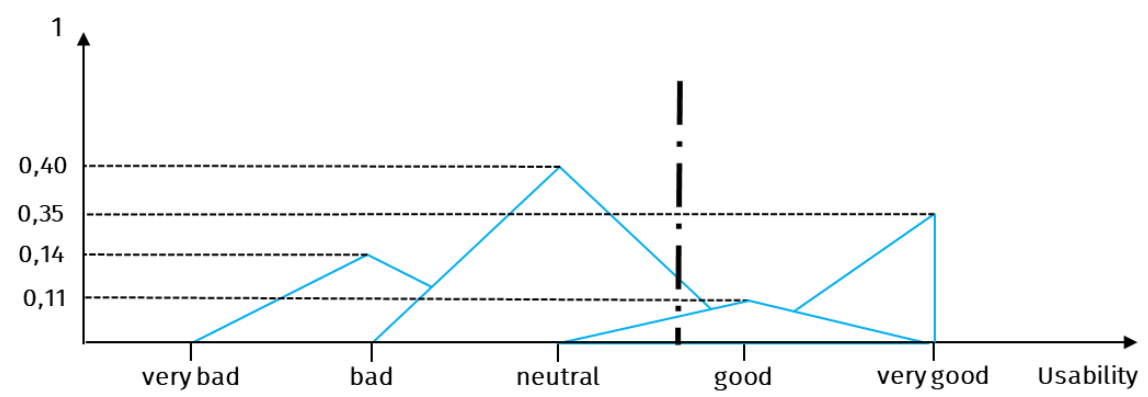

Figure 4. Aggregation of usability according to Table 2

If the scale from "very bad" to "very good" is assigned from zero to one, the result for usability after defuzzification is 0.66 . In this example, no weighting of the subcategories was considered.

\section{A case study}

In this section, we present two different coffee machines as an example the evaluation method for fuzzy sets. The two products were evaluated in a questionnaire on simple products. Twenty-seven students from the field of mechanical engineering took part in the evaluation. Functionality, usability, product gestalt and reliability were tested based on given technical data and image sections.

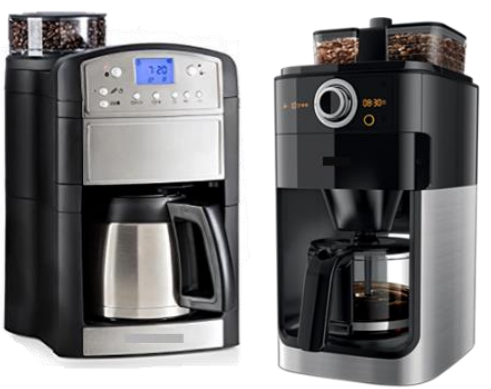

Figure 5. Products of the case-study

A total of seventeen items were provided for both products, which were evaluated on a scale of -2 to +2 . The attributes presented in Section 3 were further specified in some cases to make them easier for participants to understand. In particular, robustness is further subdivided into error susceptibility, maintenance ability and resource consumption. In addition, two items on familiarity have been added under the heading "Experience" to supplement the expectation conformity. An overview of all subcategories used as well as the presentation of the collected results of the questionnaire is shown in Figure 6 . The points were determined via the mean value.

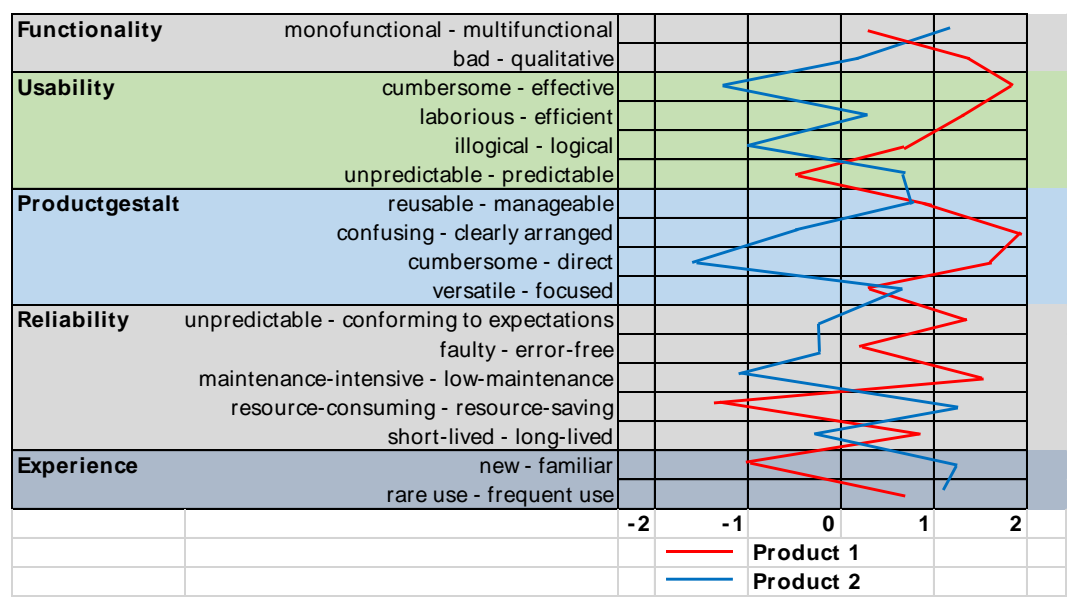

Figure 6. Items of the questionnaire 
The fact that there are only two valuation parameters to choose from means that the resulting combinations of the rule matrix are kept as low as possible. Nevertheless, the rule matrix of reliability results from five items to be evaluated in 32 possible evaluation scenarios. Because of this high number of combinations, it is recommended to evaluate robustness separately from expected conformity and life span in a first step. This sets the evaluation structure one level lower and only has to be evaluated with eight possible scenarios. The resulting distribution is then not subjected to any defuzzification, but is included in the next evaluation as new input for the next higher level. This is because each characteristic represents a possible state that occurs with the corresponding level of affiliation.

Each item was summarized via the affiliation functions and the respective rule matrix and mapped within the respective attributes. Figure 7 shows the assignment of the four subcategories for the first coffee machine.
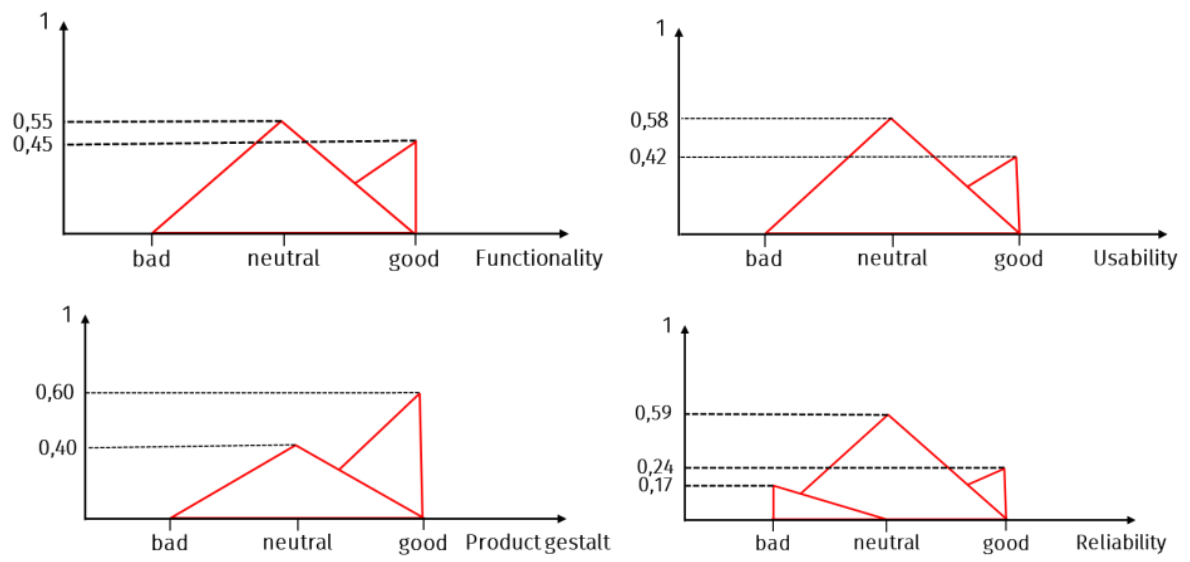

Figure 7. Affiliation function of functionality. usability, product gestalt and reliability

It is evident that, with the exception of reliability, all evaluations are distributed in the neutral to good range. Only the reliability belongs to a subset of the bad evaluations, which can be attributed to the consumption of resources.

In the last step, these four attributes are aggregated and combined to form a simplicity index. The rule matrix included 81 possible affiliations, of which 24 are used for the first coffee machine due to the strong distribution between "neutral" and "good". Similar to Figure 4, a scale in five interval steps is selected. Four of the classifications are "simple", eight are "less simple" and twelve are "neutral". The largest set is arranged with a distribution of 0.5 in the "neutral" range, followed by "less simple" with 0.33 and "simple" with the affiliation of 0.17 . The same procedure was followed for the evaluation of the second coffee machine. Due to the much broader distribution of the evaluated items, the result was more scattered, whereby a total of 36 of 81 rule sets were considered, which were summarized in five interval steps. Figure 8 shows the resulting aggregations for the two coffee machines.

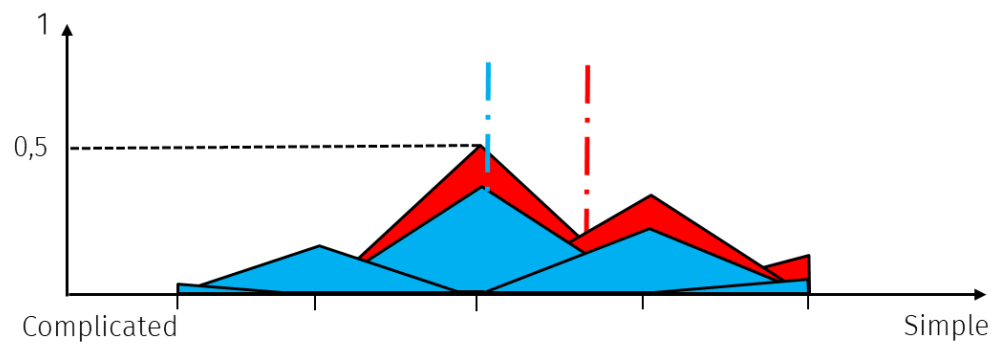

Figure 8. Aggregation of the simplicity-index

In contrast to the first coffee machine, the aggregation of the second machine is much more widely spread. The focus is also in the "neutral" range, but it is distributed over the whole interval. A defuzzification of the two evaluations with the help of the centroid of area in the last step results in a simplicity index of 0.69 for the first coffee machine and 0.51 for the second. 


\section{Discussion}

As shown in the case study, we were able to apply the principle of fuzzy quantities within the approach of a decision making system to evaluate simple products from the user's point of view. This approach makes it possible to convert the evaluation of fuzzy linguistic parameters into a deterministic indicator. The primary advantage here is the rule matrix. It can be used to define and aggregate complex relationships. While after use a person can give an assessment of the simplicity of the product without problems based on the properties of the product, it is mathematically difficult to understand which attributes of the product lead to this statement. It may be that the usability of the product had weaknesses, but this was compensated by both reliability and product gestalt, and thus the whole product is still perceived as simple. The rule matrix represents all possible combinations at different attribute quality levels and defines a resulting simplicity for each occurrence.

A problem is the number of combinatorial possibilities. If the simplicity is divided into four attributes with three subcategories each, which are divided into three evaluation items, there are twenty-seven different combinations per attribute on the first level. For summarizing the attributes, eighty-one different combinations are possible. Together with all four attributes, there are 189 required rules. If more evaluation items or more subcategories are used, the possible combinatory quickly become unmanageable.

\section{Conclusion and outlook}

In this paper we presented a concept for evaluating product simplicity. A list of the relevant areas influencing the definition was created on the basis of a detailed literature review. From the resulting definition eight attributes of the IDE were adopted, which were used as evaluation criteria. We combined these attributes with the evaluation approach of fuzzy quantities to create a simplicity index from the user's point of view. It turned out that particularly fuzzy sets provide a good insight into the cause-effect relationships within an evaluation system.

In the next steps a further verification of the affiliation functions will be necessary. Their quality has a decisive influence on the final result. It could also be interesting to apply the used principle on the provider's point of view. Thanks to the logical connections of the rule matrix, a comprehensible evaluation could also be made here.

Furthermore, by considering the approaches of the user and provider, it is potentially possible that conclusions about simple products in usage can be traced back to the simplicity of development and vice versa. This would make it possible to select key development nodes in a later Design for Simplicity in order to generate simplicity for both the provider and the user.

Further research will be done on possible strategies and methods for simplifying a product. Thus, in addition to the simplicity index, suitable instructions for action could be evaluated and provided. Moreover, the evaluation in this paper did not face the influence of the user's experience of the product. It is questionable what influence the user's experience and knowledge have on the evaluation of the simplicity of a product.

\section{Acknowledgment}

This research work has been funded by Deutsche Forschungsgemeinschaft (support code VA 134 13-1).

\section{References}

Breiing, A. and Knosala, R. (1997), Bewerten technischer Systeme, Springer Heidelberg.

Brügger, C., Hartschen, M. and Scherer, J. (2013), Simplicity: Prinzipien der Einfachheit; Strategien für einfache Produkte, Dienstleistungen und Prozesse, 3. Aufl., Gabal-Verlag, Offenbach.

Choi, J.H. and Lee, H.-J. (2012), "Facets of simplicity for the smartphone interface. A structural model", International Journal of Human-Computer Studies, Vol. 70 No. 2, pp. 129-142.

Dombrowski, U. and Mielke, T. (2015), Ganzheitliche Produktionssysteme: Aktueller Stand und zukünftige Entwicklungen, VDI-Buch, Springer Vieweg, Berlin.

Ehrlenspiel, K. and Meerkamm, H. (2013), Integrierte Produktentwicklung: Denkabläufe, Methodeneinsatz, Zusammenarbeit, 5., überarb. und erw. Aufl., Hanser, München.

Feldhusen, J. and Grote, K.-H. (2013), Pahl/Beitz Konstruktionslehre: Methoden und Anwendung erfolgreicher Produktentwicklung, 8., vollständig überarbeitete Auflage, Springer Vieweg, Berlin, Heidelberg. 
Geis, T. and Johner, C. (2015), Usability Engineering als Erfolgsfaktor: Effizient IEC 62366- und FDA-konform dokumentieren, Beuth Praxis, Beuth, Berlin.

Güllich, H.-P. (1997), Fuzzy-Expertensysteme zur Beurteilung von Kreditrisiken, Deutscher Universitätsverlag, Wiesbaden.

Hartmann, S. (2013), Ein Beitrag zur frühzeitigen Abschätzung der Produktkomplexität und zur Definition einfacher Produkte, Zugl.: Magdeburg, Univ., PhD., Magdeburg.

Hassenzahl, M. (2004), "The Interplay of Beauty, Goodness, and Usability in Interactive Products", HumanComputer Interaction, Vol. 19 No. 4, pp. 319-349.

Helfrich, C. (2015), Das Prinzip Einfachheit: Reduzieren Sie die Komplexität, Praxiswissen Wirtschaft, expert, Renningen.

Hubka, V. (1984), Theorie Technischer Systeme: Grundlagen einer wissenschaftlichen Konstruktionslehre, Hochschultext, Zweite, völlig neu bearbeitete und erweiterte Auflage, Springer, Berlin, Heidelberg.

Maeda, J. (2006), The laws of simplicity, MIT Press, Mass, Cambridge.

Norman, D.A. (2013), The design of everyday things, Revised and expanded edition, Basic Books, New York.

Olbrich, R. and Battenfeld, D. (2005), "Variantenvielfalt und Komplexität - kostenorientierte vs. marktorientierte Sicht", der markt, Vol. 44 No. 3-4, pp. 161-173.

Pahl, G. et al. (2007), Konstruktionslehre: Grundlagen erfolgreicher Produktentwicklung; Methoden und Anwendung, 7. Aufl., Springer, Heidelberg.

Pilz, F., Vajna, S. and Schabacker, M. (2018), "Achieving Simplicity: Development and Design of Simple Products", in Volume 7: 30th International Conference on Design Theory and Methodology, Quebec, Canada, American Society of Mechanical Engineers.

Preim, B. and Dachselt, R. (2015), Interaktive Systeme: Band 2: User Interface Engineering, eXamen.press, 2. Aufl., Springer Vieweg, Berlin.

Quirmbach, S.M. (2013), Suchmaschinen: User Experience, Usability und nutzerzentrierte Website-Gestaltung, X.media.press, Springer, Berlin, Heidelberg.

Robier, J. (2016), Das einfache und emotionale Kauferlebnis: Mit Usability, User Experience und Customer Experience anspruchsvolle Kunden gewinnen, 1. Auflage, Springer Gabler, Wiesbaden.

Rommelfanger, H. (1993), "Fuzzy-Logik basierte Verarbeitung von Expertenregeln”, OR Spektrum, Vol. 15 No. 1 , pp. 31-42.

Rommelfanger, H.J. and Eickemeier, S.H. (2002), Entscheidungstheorie: Klassische Konzepte und FuzzyErweiterungen, Springer-Lehrbuch, Springer, Heidelberg.

Schneider, B. (2005), Design - eine Einführung: Entwurf im sozialen, kulturellen und wirtschaftlichen Kontext, De Gruyter, Basel.

Seeger, H. (2005), Design technischer Produkte, Produktprogramme und -systeme: Industrial Design Engineering, 2., bearb. und erw. Aufl., Springer-Verlag Berlin Heidelberg, Berlin, Heidelberg.

Urakami, J. and Vajna, S. (2018), "Human Centricity in Integrated Design Engineering", in 15th International Design Conference, Design Conference Proceedings, Proceedings of DESIGN 2018, University of Zagreb, Croatia, 2018, pp. 679-690.

Vajna, S. (2014), Integrated Design Engineering: Ein interdisziplinäres Modell für die ganzheitliche Produktentwicklung, Springer Heidelberg.

Vajna, S. (2015), "Attributes in Integrated Design Engineering - A new way to describe both performance capability and behaviour of a product", In: Weber, C., Husung, S., Cantamessa, M., Cascini, G., Marjanovic, D. and Venkataraman, S. (Eds.), Design theory and research methodology design processes, Design Society, Glasgow, pp. 127-136.

Womack, J.P., Jones, D.T. and Roos, D. (1992), Die zweite Revolution in der Autoindustrie: Konsequenzen aus der weltweiten Studie aus dem Massachusetts Institute of Technology, 5. Aufl., Campus-Verlag, Frankfurt/Main.

Zeh, N. (2010), Erfolgsfaktor Produktdesign, Zugl.: Köln, Univ., PhD., 2009, Beiträge zum Produkt-Marketing, Vol. 45, Förderges. Produkt-Marketing e.V, Köln. 